\title{
Research article Deep catalytic oxidation of benzene, toluene, ethyl acetate over Pd/SBA-15 catalyst: reaction behaviors and kinetics
}

\author{
Chi He, ${ }^{1,2}$ Lin Yue, ${ }^{1}$ Xinyan Zhang, ${ }^{1}$ Peng Li, ${ }^{1}$ Baojuan Dou, ${ }^{1}$ Chunyan Ma ${ }^{1}$ and Zhengping Hao ${ }^{1}$ * \\ ${ }^{1}$ Department of Environmental Nano-materials, Research Center for Eco-Environmental Sciences, Chinese Academy of Sciences, Beijing 100085, P. R. \\ China \\ ${ }^{2}$ Key Lab of Urban Environment and Health, Institute of Urban Environment, Chinese Academy of Sciences, Xiamen 361021, P. R. China
}

Received 10 January 2011; Revised 16 June 2011; Accepted 22 June 2011

\begin{abstract}
This work aimed at investigating the reaction behaviors and kinetics of catalytic oxidation of benzene, toluene, and ethyl acetate over Pd/SBA-15 catalyst. Results for single components show that toluene $\left(T_{50}=185-215^{\circ} \mathrm{C}\right)$ is more easily oxidized than ethyl acetate $\left(T_{50}=220-255^{\circ} \mathrm{C}\right)$ and benzene $\left(T_{50}=215-290{ }^{\circ} \mathrm{C}\right)$. The conversion of toluene and benzene decreases continuously as their inlet concentrations are increased. The conversion of ethyl acetate increases slightly when its feed concentration increases in a small range, while this trend is not kept when the concentration is further raised. Results for multicomponents reveal that the presence of benzene or toluene inhibits the conversion of ethyl acetate, and the aromatic hydrocarbons inhibit each other. Ethyl acetate has an inhibitory effect on benzene, while it is interested to note that the promotion behaviors are observed for toluene. Kinetic results of all studied volatile organic compounds obtained in the absence of diffusion limitations are fit to the Mars-van Krevelen expressions. (c) 2011 Curtin University of Technology and John Wiley \& Sons, Ltd.
\end{abstract}

KEYWORDS: Pd/SBA-15; catalytic oxidation; VOCs; mutual effects; kinetics

\section{INTRODUCTION}

Volatile organic compounds (VOCs), such as aromatic hydrocarbons and esters, emitted from many chemical and industrial processes are dangerous for public health and the environment. ${ }^{[1,2]}$ There is a need to develop novel VOC control techniques which are not only efficient but also economical. As is known, deep catalytic oxidation technology has been widely applied in air pollution control, such as the treatment of offgas from chemical plants, odor emissions, and solvents evaporation, ${ }^{[3]}$ as it can eliminate organic pollutants at moderate temperatures and can reduce the harmful organic by-products. ${ }^{[4]}$ Currently, many types of catalysts, such as noble-metal-based catalysts, ${ }^{[5-8]}$ metal oxides, ${ }^{[6,9-11]}$ pillared clays, ${ }^{[5,12,13]}$ and porous materials supported catalysts, ${ }^{[8,14-20]}$ have been developed to achieve these requirements. Particularly, Pd-supported catalysts are extensively examined as Pd catalyst is promising for practical applications in hydrocarbon total combustion due to its high activity at relatively low temperatures and high tolerance to moisture. ${ }^{[21,22]}$ Different

*Correspondence to: Zhengping Hao, Department of Environmental Nano-materials, Research Center for Eco-Environmental Sciences, Chinese Academy of Sciences, Beijing 100085, P. R. China.

E-mail: zpinghao@rcees.ac.cn types of supports such as porous materials, zirconia, alumina, and silica are comprehensively investigated in hydrocarbons catalytic oxidation ${ }^{[23-26]}$ as the supports are an important component for the Pd-loaded catalysts, which can profoundly affect the active species generation and the catalytic performance. ${ }^{[27]}$ Among them, mesoporous materials (such as SBA-15) possess narrow pore size distribution (PSD), high surface area $\left(>700 \mathrm{~m}^{2} / \mathrm{g}\right)$ and potential ability to inhibit active particles growth and aggregation in their pores appear to be one of the best support for Pd-loaded catalysts. ${ }^{[28,29]}$ Comparing with mesoporous materials, metal oxide has relatively lower surface area. Moreover, Pd as well as other metal nanoparticles is often unstable (sintering) on the oxide supports at elevated reaction temperatures and their activity rapidly decays. ${ }^{[30]}$

In practical applications, gas streams containing VOC mixtures with different concentrations and compositions should be handled. Thus, it is difficult to predict the combustion behavior and to control the oxidation efficiency, as the 'mixed effect' may be significant. On the other hand, the development of a suitable kinetic model for VOC combustion is also a challenging issue as each VOC behaves differently over catalysts. Some reports have been published regarding the kinetic behaviors of VOC combustion over 
metal oxides, perovskites and zeolites. ${ }^{[31-34]}$ However, literature involving kinetic studies for the VOC combustion over noble-metal-loaded mesoporous catalysts is rather limited. Moreover, most kinetic studies have been carried out at low VOC concentrations $(<1000 \mathrm{ppm})$, while the concentrations of industrial effluents may be much higher.

The presence of VOC mixture which is usual for "end-of-pipe" pollution control may affect the design criteria, operation control, and performance of catalytic incinerators. ${ }^{[31]}$ The existing catalytic incinerators can be designed by considering the VOC compound that is the most difficult one to be oxidized or the most environmental concern. Unfortunately, this in some cases might result in overdesigning the catalytic reactor as the promotion and inhibition effect probably occurs in most multicomponent VOC system. ${ }^{[33,35]}$ It is often not possible to predict what effect one component might have on the oxidation rate of the other. Thus, the effect is normally considered on a case-to-case basis.

The current work aimed at elucidating the catalytic behavior and reaction kinetics of benzene (Bz), toluene (Tol), and ethyl acetate (EAc) over Pd-loaded mesoporous catalysts (Pd/SBA-15). Benzene, toluene, and ethyl acetate have been chosen as representatives of aromatics and esters for both their larger emission amount and toxicity. Related experiments have been carried out at VOC total concentration up to $6000 \mathrm{ppm}$, covering the concentration range of most industrial effluents. Mars-van Krevelen kinetic model was tested for its applicability in expressing the reaction rate under differential reaction conditions. These results could provide valuable information for designing and operating a catalytic system based on noblemetal-loaded mesoporous catalysts to treat a VOC containing air stream, and these experimental data should be interesting to different investigators and readers.

\section{EXPERIMENTAL}

\section{Catalyst synthesis}

In a typical synthesis of SBA-15: $1 \mathrm{~g}$ of P123 $\left(\mathrm{EO}_{20} \mathrm{PO}_{70} \mathrm{EO}_{20}\right.$, Sigma-Aldrich) was dissolved in

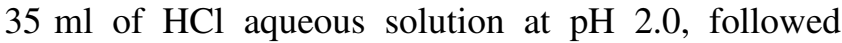
by addition of $2.3 \mathrm{ml}$ TEOS under stirring at $35^{\circ} \mathrm{C}$ for $24 \mathrm{~h}$. Then the mixture was transferred into an autoclave and aged at $100{ }^{\circ} \mathrm{C}$ for $48 \mathrm{~h}$. The solid product was filtered and thoroughly washed with deionized water, and dried at $100^{\circ} \mathrm{C}$ overnight. Then the material was calcined in a muffle furnace at $550^{\circ} \mathrm{C}$ for $6 \mathrm{~h}$ with a heating rate of $5^{\circ} \mathrm{C} / \mathrm{min}$, and the mesoporous SBA- 15 was finally obtained.

Pd/SBA-15 catalyst with a Pd nominal loading of $0.30 \mathrm{wt} \%$ was prepared by impregnating the as-prepared
SBA-15 material with a $\mathrm{PdCl}_{2}$ aqueous solution and then drying at $100^{\circ} \mathrm{C}$ overnight, followed by calcination at $500{ }^{\circ} \mathrm{C}$ for $4 \mathrm{~h}$ and being reduced in a pure $\mathrm{H}_{2}$ stream (30 $\mathrm{ml} / \mathrm{min}$ ) at $480{ }^{\circ} \mathrm{C}$ for $2 \mathrm{~h}$.

\section{Catalyst characterization}

X-ray diffraction (XRD) pattern was recorded on a Rigaku TTR2 powder diffraction system using $\mathrm{Cu}-\mathrm{K} \alpha$ radiation $(\lambda=0.15418 \mathrm{~nm})$ in the $2 \theta$ range of $0.7-7^{\circ}$ with a scanning rate of $0.5^{\circ} \mathrm{min}$. The Pd loading of as-synthesized catalyst was determined by inductively coupled plasma optical emission spectroscopy (ICPOES) analysis performed on an OPTIMA 2000 analysis system. Scanning electron microscopy (SEM) was performed on a Hitachi S-3000N instrument operating at $20 \mathrm{kV}$. Transmission electron microscope (TEM) images were collected on a Hitachi H-7500 microscope operating at an accelerating voltage of $80 \mathrm{kV}$. Scanning transmission electron microscope (STEM) images were recorded on a FEI Tecnai G2 F20 UTWIN microscope operating at an accelerating voltage of $200 \mathrm{kV}$. Temperature programmed reduction (TPR) experiments were performed on a Micromeritics chemisorb 2720. Prior to reduction, $0.1 \mathrm{~g}$ of the catalyst was dried in a helium flow $(50 \mathrm{ml} / \mathrm{min})$ at $300{ }^{\circ} \mathrm{C}$ for $1 \mathrm{~h}$. Then the sample was reduced under a $\mathrm{H}_{2} / \mathrm{He}\left(2 \% / 98 \%\right.$ in v/v) mixture from 25 to $500^{\circ} \mathrm{C}$ with a heating rate of $10^{\circ} \mathrm{C} / \mathrm{min}$. The coke property of the used Pd/SBA-15 catalyst was analyzed by TG analyzer (Setaram Labsys). The $\mathrm{N}_{2}$ adsorption/desorption isotherm was measured at $77 \mathrm{~K}$ on a NOVA1200 gas sorption analyzer. The sample was degassed in vacuum at $300{ }^{\circ} \mathrm{C}$ for $3 \mathrm{~h}$ before measurement. The total pore volume $\left(D_{\mathrm{v}}\right)$ was estimated from the amount of nitrogen adsorbed at a relative pressure $\left(P / P_{0}\right)$ of ca. 0.99 . The surface area $\left(S_{\mathrm{BET}}\right)$ was calculated with the Brunauer-Emmett-Teller (BET) method, the PSD was derived from the desorption branch of the $\mathrm{N}_{2}$ isotherm using the Barrett-Joyner-Halenda (BJH) method. The palladium dispersion was assessed by chemisorption of $\mathrm{H}_{2}$ at $25^{\circ} \mathrm{C}$, assuming that each exposed $\mathrm{Pd}$ atom adsorbs one hydrogen atom. ${ }^{[34]}$ The mean Pd crystallite size was further estimated from the equation: $d(\mathrm{~nm})=$ $112 /$ (percentage of Pd exposed), ${ }^{[5]}$ assuming that the Pd crystallites were spherical with a surface atom density of $1.27 \times 10^{9}$ atoms $/ \mathrm{m}^{2}$.

\section{Catalytic oxidation activities}

All evaluation experiments were performed in a continuous-flow fixed-bed reactor under atmospheric pressure. It consists of a stainless steel tube $(6 \mathrm{~mm}$ i.d.) charged with the required amount of catalyst. The VOCladen gas was generated by bubbling air through the 
VOC saturators, and then further diluted with another air steam before reaching the reaction bed. The reactor temperature of the catalyst bed and tubular electric furnace were monitored automatically by E-type thermocouples, respectively.

In each test, $300 \mathrm{mg}$ of catalyst (40-60 mesh) was placed into the center of the reactor and the total flow rate was kept at $300 \mathrm{ml} / \mathrm{min}$, i.e., gas hourly space velocity (GHSV) of $26000 \mathrm{~h}^{-1}$. An on-line gas chromatograph equipped with an FID was used to analyze the VOC concentrations in the feed and effluent streams. Before each test, the catalytic bed temperature was raised to $130^{\circ} \mathrm{C}$ with the feed stream passing (no oxidation was detected) and stabilized for $30 \mathrm{~min}$. Then the catalyst bed temperature was raised with a heating rate of $5{ }^{\circ} \mathrm{C} / \mathrm{min}$ to the next point and stabilized for $20 \mathrm{~min}$ prior to recording the GC data for the effluent gas. A portion of effluent stream was analyzed on line by an Agilent gas chromatograph equipped with an FID and a TCD. VOC concentrations in the feed and effluent streams were determined on the FID after being separated in an AB-GASPRO capillary column. $\mathrm{CO}$ and $\mathrm{CO}_{2}$ in the effluent stream were separated by a TDX-01 column and were analyzed on the TCD. The VOC concentrations on the effluent were determined by GC when the composition and concentration of VOCs in the inlet streams were varied, as detailed in Table 1. Data for kinetic study were obtained by varying the concentrations of VOCs in the feed streams. All kinetics experiments were conducted under oxygen-rich conditions and the kinetic data were obtained with the conversion below 25\%. ${ }^{[36]}$ No CO has been detected in any experiment.

\section{RESULTS AND DISCUSSION}

\section{Structural and textural properties of Pd/SBA-15 catalyst}

Figure 1 shows the XRD and $\mathrm{N}_{2}$ adsorption/desorption result of $\mathrm{Pd} / \mathrm{SBA}-15$. Figure $1 \mathrm{~A}$ reveals that the catalyst has three well-resolved characteristic diffraction peaks, indexed as the (100), (110), and (200) plane diffractions of the two-dimensional hexagonal mesostructure. ${ }^{[37]}$ Figure $1 \mathrm{~B}$ shows that the assynthesized sample exhibits type IV adsorption/ desorption isotherm according to the IUPAC classification, ${ }^{[38]}$ which is a typical characteristic of mesoporous materials.

The SEM image of Pd/SBA-15 (Fig. 2A) shows that each particle of the catalyst has a cylindrical form with $3-5 \mu \mathrm{m}$ in diameter and consists of packages of cylindrical fibers. The diameter and length of one fiber is about $500 \mathrm{~nm}$ and $2-50 \mu \mathrm{m}$, respectively. This means that more than 1500 nanotubular cylindrical
Table 1. Experimental operating conditions in the present work.

\begin{tabular}{|c|c|c|c|c|}
\hline $\begin{array}{l}\text { Experiment } \\
\text { no. }\end{array}$ & Benzene $^{\mathrm{a}}$ & Toluene $^{\mathrm{a}}$ & $\begin{array}{c}\text { Ethyl } \\
\text { acetate }^{\mathrm{a}}\end{array}$ & $\begin{array}{l}\text { Total } \\
\text { VOC }^{\mathrm{a}}\end{array}$ \\
\hline \multicolumn{5}{|l|}{ Set I single } \\
\hline 1 & 880 & 0 & 0 & 880 \\
\hline 2 & 1600 & 0 & 0 & 1600 \\
\hline 3 & 3610 & 0 & 0 & 3610 \\
\hline 4 & 0 & 690 & 0 & 690 \\
\hline 5 & 0 & 1015 & 0 & 1015 \\
\hline 6 & 0 & 1550 & 0 & 1550 \\
\hline 7 & 0 & 0 & 970 & 970 \\
\hline 8 & 0 & 0 & 1530 & 1530 \\
\hline 9 & 0 & 0 & 3670 & 3670 \\
\hline \multicolumn{5}{|l|}{ Set II binary } \\
\hline 10 & 1650 & 1027 & 0 & 2677 \\
\hline 11 & 3600 & 1013 & 0 & 4613 \\
\hline 12 & 1500 & 0 & 987 & 2487 \\
\hline 13 & 3120 & 0 & 993 & 4133 \\
\hline 14 & 1488 & 750 & 0 & 2238 \\
\hline 15 & 1513 & 1450 & 0 & 2963 \\
\hline 16 & 0 & 674 & 1008 & 1682 \\
\hline 17 & 0 & 1523 & 991 & 2514 \\
\hline 18 & 1537 & 0 & 1122 & 2659 \\
\hline 19 & 1479 & 0 & 3920 & 5399 \\
\hline 20 & 0 & 1040 & 1550 & 2590 \\
\hline 21 & 0 & 982 & 3670 & 4652 \\
\hline \multicolumn{5}{|c|}{ Set III Ternary } \\
\hline & 3150 & 1495 & 670 & 5315 \\
\hline 23 & 710 & 1483 & 1740 & 3933 \\
\hline 24 & 740 & 1547 & 930 & 3217 \\
\hline 25 & 3210 & 1477 & 1230 & 5917 \\
\hline
\end{tabular}

${ }^{a}$ VOCs concentrations, which are expressed in $\mathrm{ppm}, \mathrm{mol} / \mathrm{mol}$.

pores are hexagonally packed in each fiber. The TEM image in Fig. 2B reveals that the sample possesses well-ordered structure with uniform pore size of ca. $6 \mathrm{~nm}$. No Pd particles can be observed, indicating that the Pd atoms are well-dispersed over the support. Herein, the STEM was further performed to confirm the Pd particles dispersion, and the result reveals that all $\mathrm{Pd}$ atoms are well-dispersed over the support with the diameter of 1-3 nm (Fig. 2C). Figure 2D shows the $\mathrm{H}_{2}$-TPR of the synthesized catalysts. Only a negative peak (around $70^{\circ} \mathrm{C}$ ) can be observed due to the desorption of weakly adsorbed hydrogen or the decomposition of $\mathrm{PdH}_{\mathrm{x}},{ }^{[39,40]}$ indicating that $\mathrm{PdCl}_{2}$ or $\mathrm{PdO}$ gets reduced easily to metal $\mathrm{Pd}$ in $\mathrm{H}_{2}$ atmosphere. The physicochemical characteristics of $\mathrm{Pd} / \mathrm{SBA}-15$ are summarized in Table 2 . The catalyst possesses a narrow PSD (centered at $6.5 \mathrm{~nm})$ and thick pore wall $(3.8 \mathrm{~nm})$, and the actual Pd content of synthesized catalyst $(0.29$ $\mathrm{wt} \%)$ is close to the theoretic Pd loading (0.3 wt\%). Moreover, the $\mathrm{H}_{2}$ chemisorptions result reveals that the average Pd crystallite size over the support is ca. $1.7 \mathrm{~nm}$, which is in agreement with the STEM result. 

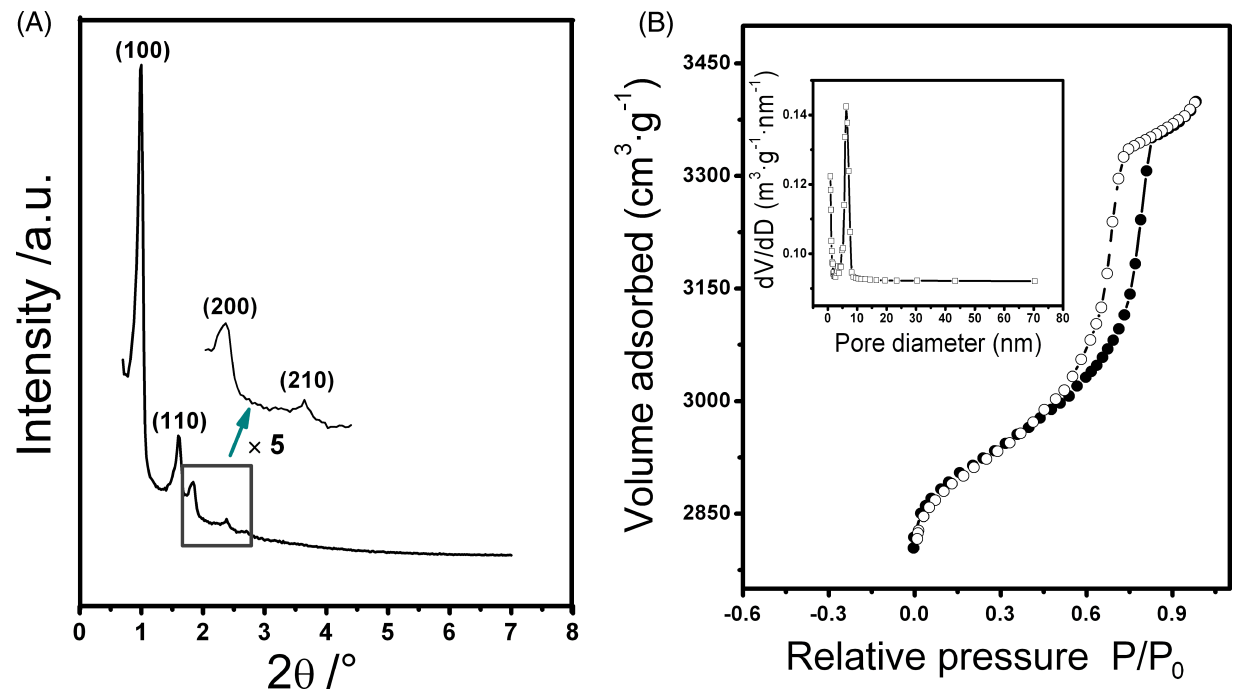

Figure 1. X-ray diffraction patterns (A) and $\mathrm{N}_{2}$ adsorption/desorption isotherms (B) (inset: pore size distribution) of $\mathrm{Pd} / \mathrm{SBA}-15$ catalyst. This figure is available in colour online at www.apjChemEng.com.

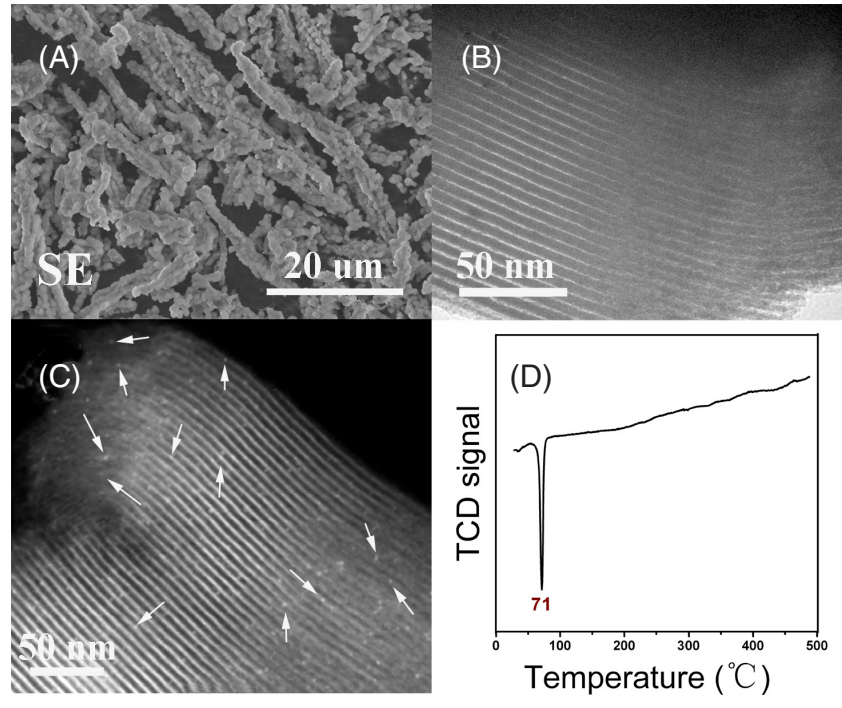

Figure 2. Representative SEM, TEM, STEM, and $\mathrm{H}_{2}$-TPR images of Pd/SBA-15 catalysts: (A) SEM, (B) TEM, (C) STEM, and (D) $\mathrm{H}_{2}$-TPR. This figure is available in colour online at www.apjChemEng.com.

\section{Catalyst stability and diffusion limitations}

\section{Catalyst stability}

Catalyst deactivation was evaluated by exposing $\mathrm{Pd} /$ SBA-15 to $1520 \mathrm{ppm}$ of benzene, $1450 \mathrm{ppm}$ of ethyl acetate, and $1500 \mathrm{ppm}$ of toluene at different temperatures. Figure $3 \mathrm{~A}$ illuminates the VOC conversion as a function of time-on-stream for $50 \mathrm{~h}$. The data reveal that the conversion of toluene, ethyl acetate, and benzene decreased from $59 \%, 35.9 \%$, and $25.7 \%$ to $57.8 \%$, $34.4 \%$, and $25.6 \%$ after $50 \mathrm{~h}$ exposition to the VOC, indicating that the catalyst possesses good hydrothermal stability and the catalyst deactivation in reaction conditions would not influence the kinetic data. Thermal analysis has been used to monitor the coke property of the used catalyst (Fig. 3B). The used sample just shows one steps of weight loss when heated under airflow $\left(40-170^{\circ} \mathrm{C}\right)$, due to desorption of physisorbed water. It is noteworthy that no mass loss can be found when the temperature is higher than $200{ }^{\circ} \mathrm{C}$, indicating that no coke was formed on the catalyst.

\section{Transport effect}

The kinetic experiments should be carried out in the absence of mass and heat transfer control, and the diffusion limitations was checked using the criteria proposed by Ordóñez et al.$^{[31]}$ First of all, the effect of reactant external transport was evaluated by comparing the conversion curves of a set of experiments where only the feed gas linear velocity were varied from $0.53 \times 10^{3}$ to $1.59 \times 10^{3} \mathrm{~m} / \mathrm{s}$, and the other evaluation conditions were that the GHSV was fixed at $26000 \mathrm{~h}^{-1}$, the reaction temperature was set at $200{ }^{\circ} \mathrm{C}$ for benzene and ethyl acetate, and $180^{\circ} \mathrm{C}$ for toluene, and the particle diameter of catalyst was 60 mesh. The feeding concentrations of benzene, ethyl acetate, and toluene were 1510, 1500, and $1480 \mathrm{ppm}$, respectively. The test result reveals that changing the inlet gas flow rate was not obviously effects VOC conversion, as depicted in Fig. 4A, indicating that the catalytic system was operated in the absence of the external diffusion limitation. The effects of internal transport were evaluated by repeating a set of process conditions while employing different catalyst diameters from 20 to 80 mesh. The other evaluation conditions were kept the same (the feed gas linear velocity was kept at $1.06 \times 10^{3} \mathrm{~m} / \mathrm{s}$ ). It was observed that the VOC conversion was lower when the average particle 
Table 2. Physicochemical properties of catalyst.

\begin{tabular}{lcccccccc}
\hline Sample & $\begin{array}{c}\mathrm{Pd}^{\mathrm{a}} \\
(\mathrm{wt} \%)\end{array}$ & $\begin{array}{c}S_{\mathrm{BET}}{ }^{\mathrm{b}} \\
\left(\mathrm{m}^{2} / \mathrm{g}\right)\end{array}$ & $\begin{array}{c}D_{\mathrm{V}^{\mathrm{c}}} \\
\left(\mathrm{cm}^{3} / \mathrm{g}\right)\end{array}$ & $\begin{array}{c}D_{\mathrm{p}}^{\mathrm{d}} \\
(\mathrm{nm})\end{array}$ & $\begin{array}{c}a_{0}{ }^{\mathrm{e}} \\
(\mathrm{nm})\end{array}$ & $\begin{array}{c}W^{\mathrm{f}} \\
(\mathrm{nm})\end{array}$ & ${\mathrm{H} / \mathrm{Pd}^{\mathrm{g}}}$ & $\begin{array}{r}D_{\mathrm{c}}{ }^{\mathrm{h}} \\
(\mathrm{nm})\end{array}$ \\
\hline Pd/SBA-15 & 0.29 & 661.9 & 1.04 & 6.5 & 10.31 & 3.8 & 0.67 & 1.7 \\
\hline
\end{tabular}

${ }^{a}$ Pd content of the catalyst obtained from ICP-OES analysis.

${ }^{\mathrm{b}}$ Specific surface area.

c Total pore volume estimated at $P / P_{0}=0.99$.

${ }^{\mathrm{d}} \mathrm{BJH}$ pore diameter calculated from the desorption branch.

e Calculated by $d_{100}, a_{0}=2 \times d_{100} / \sqrt{3}$.

${ }^{\mathrm{f}}$ All thickness, $W=a_{0}-D_{\mathrm{p}}$.

${ }^{\mathrm{g}}$ Molar ratio of adsorbed hydrogen atoms to the total palladium atoms.

${ }^{\mathrm{h}}$ Calculated diameter of the palladium crystallites based on the dispersion of $\mathrm{Pd}$.


Figure 3. (A) Conversion as a function of time-on-stream for catalytic oxidation of VOCs. $\left(C_{\mathrm{Bz}}=1520 \mathrm{ppm}, C_{\mathrm{EAc}}=1450 \mathrm{ppm}, C_{\mathrm{Tol}}=1500 \mathrm{ppm}, T_{\mathrm{Bz}}=200^{\circ} \mathrm{C}, T_{\mathrm{Tol}}=190^{\circ} \mathrm{C}\right.$, $\left.T_{\mathrm{EAC}}=240^{\circ} \mathrm{C}, \mathrm{GHSV}=26,000 \mathrm{~h}^{-1}\right) ;(\mathrm{B}) \mathrm{TG}$ profile of the used catalyst after the stability test.

(A)

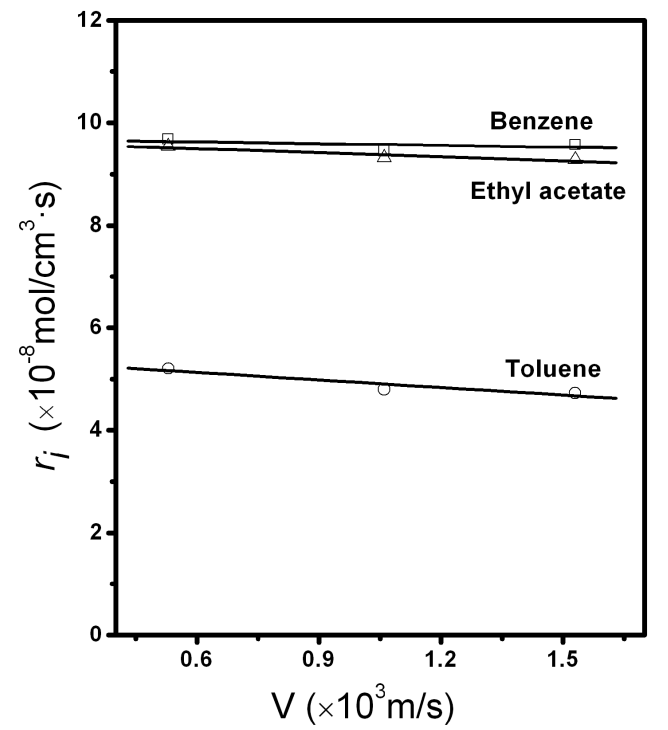

(B)

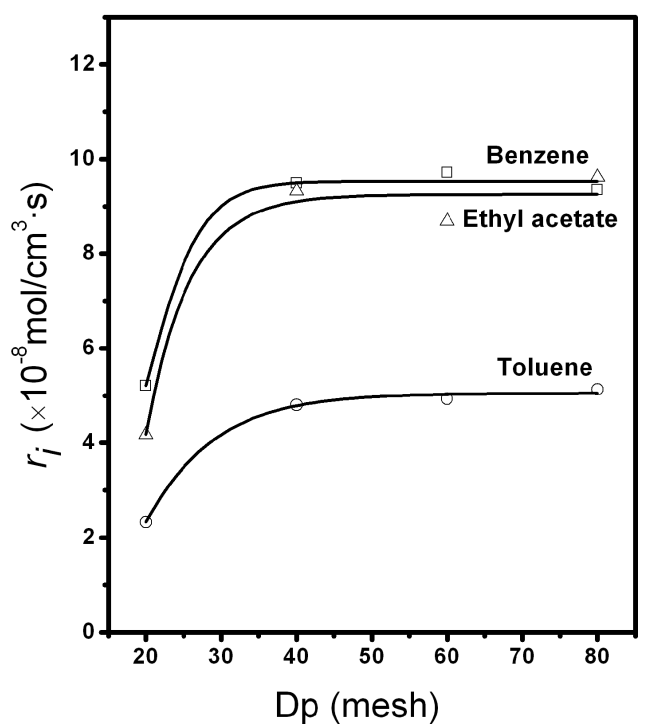

Figure 4. The evaluation results of transport effects: (A) evaluation of external diffusion resistances; (B) evaluation of internal diffusion resistances. 
diameter was 20 mesh, but the conversion was kept steady when the mean particle diameter was lower than 40 mesh (about $420 \mu \mathrm{m}$ ), suggesting that the internal diffusion limitation was absent in this work (the average particle diameter was 40-60 mesh) (Fig. 4B).

\section{Oxidation of single compound}

Total catalytic oxidation of benzene, toluene, and ethyl acetate as single component was investigated. The experimental results reveal that toluene is the most active component $\left(T_{50}=185-215^{\circ} \mathrm{C}\right)$, followed by ethyl acetate $\left(T_{50}=220-255^{\circ} \mathrm{C}\right)$ and benzene $\left(T_{50}=\right.$ $215-290^{\circ} \mathrm{C}$ ). Figure 5 shows that the VOC inlet concentration has an obvious effect on its conversion. The conversion of toluene and benzene decreases when their inlet concentrations are increased, as shown in Fig. 5A and B. For instance, benzene conversion temperature decreases dramatically (about $80^{\circ} \mathrm{C}$ ) when increase the inlet concentration from 880 to $3610 \mathrm{ppm}$. The conversion of ethyl acetate increases $\left(T_{50}\right.$ decreases from 237 to $220^{\circ} \mathrm{C}$ ) when the feed concentration increasing from 970 to $1530 \mathrm{ppm}$, while this trend is not kept $\left(T_{50}\right.$ increases from 220 to $\left.255^{\circ} \mathrm{C}\right)$ when further raising the inlet concentration to $3670 \mathrm{ppm}$ (Fig. 5C). These different behaviors are related to the interactions of the VOCs with catalyst. As is known, aromatic compounds have much stronger interaction with the catalyst surface than the linear hydrocarbons. ${ }^{[31]}$ In the case of ethyl acetate, its surface concentration over the catalyst may be the limiting factor due to its weak interaction with the catalyst surface, thus increasing its feed concentration within a certain range may cause more chemisorbed ethyl acetate molecular and lead to higher conversion. The surface oxygen concentration becomes the controlling factor when its feed concentration is increased further, and hence lower conversion. On the other hand, benzene and toluene are more easily adsorbed on the active sites in competition with oxygen, thus the concentration of the surface adsorbed oxygen is the rate-controlling factor at high VOC feed
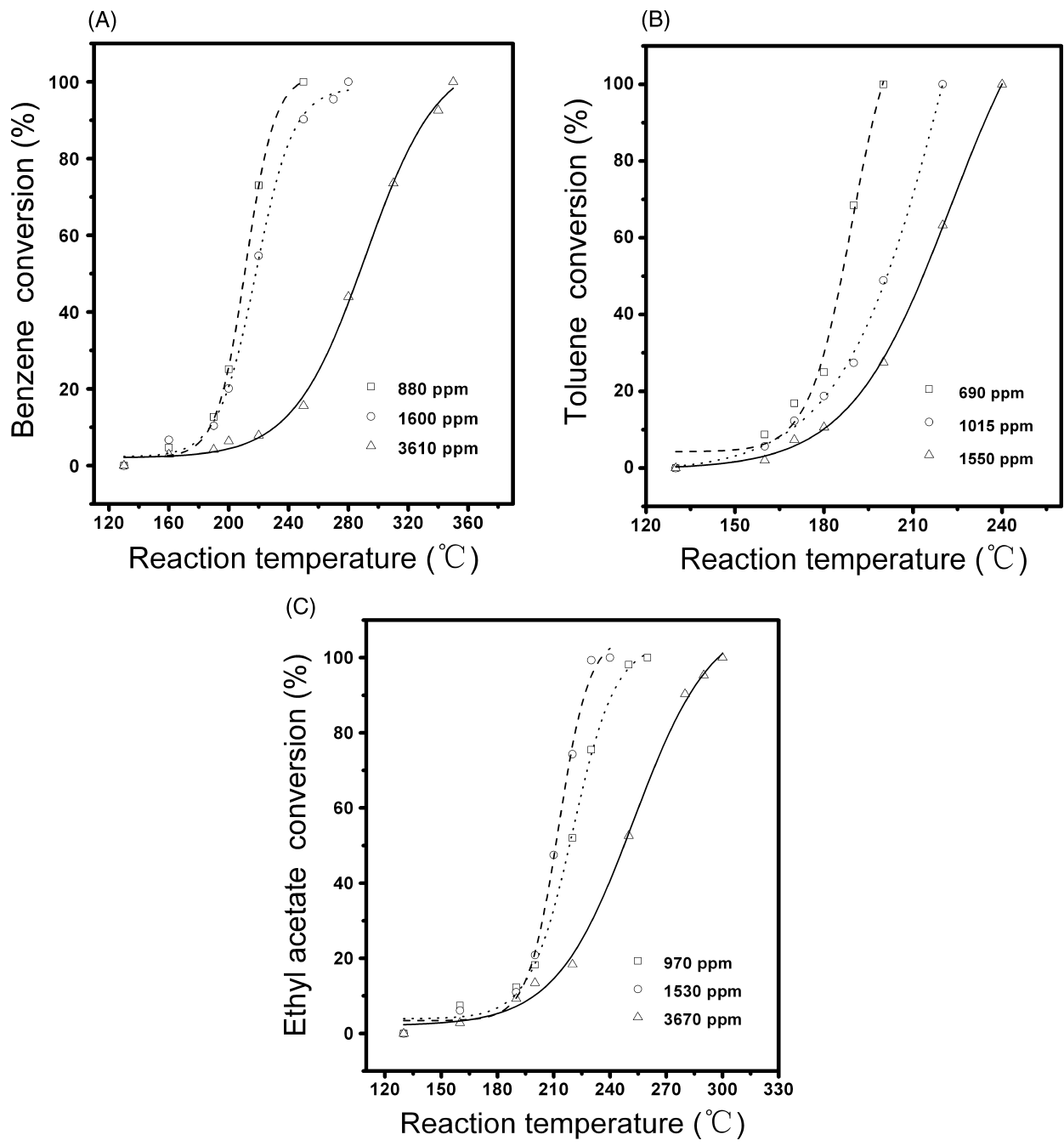

Figure 5. Catalytic oxidation of single VOCs over Pd/SBA-15 catalyst. 

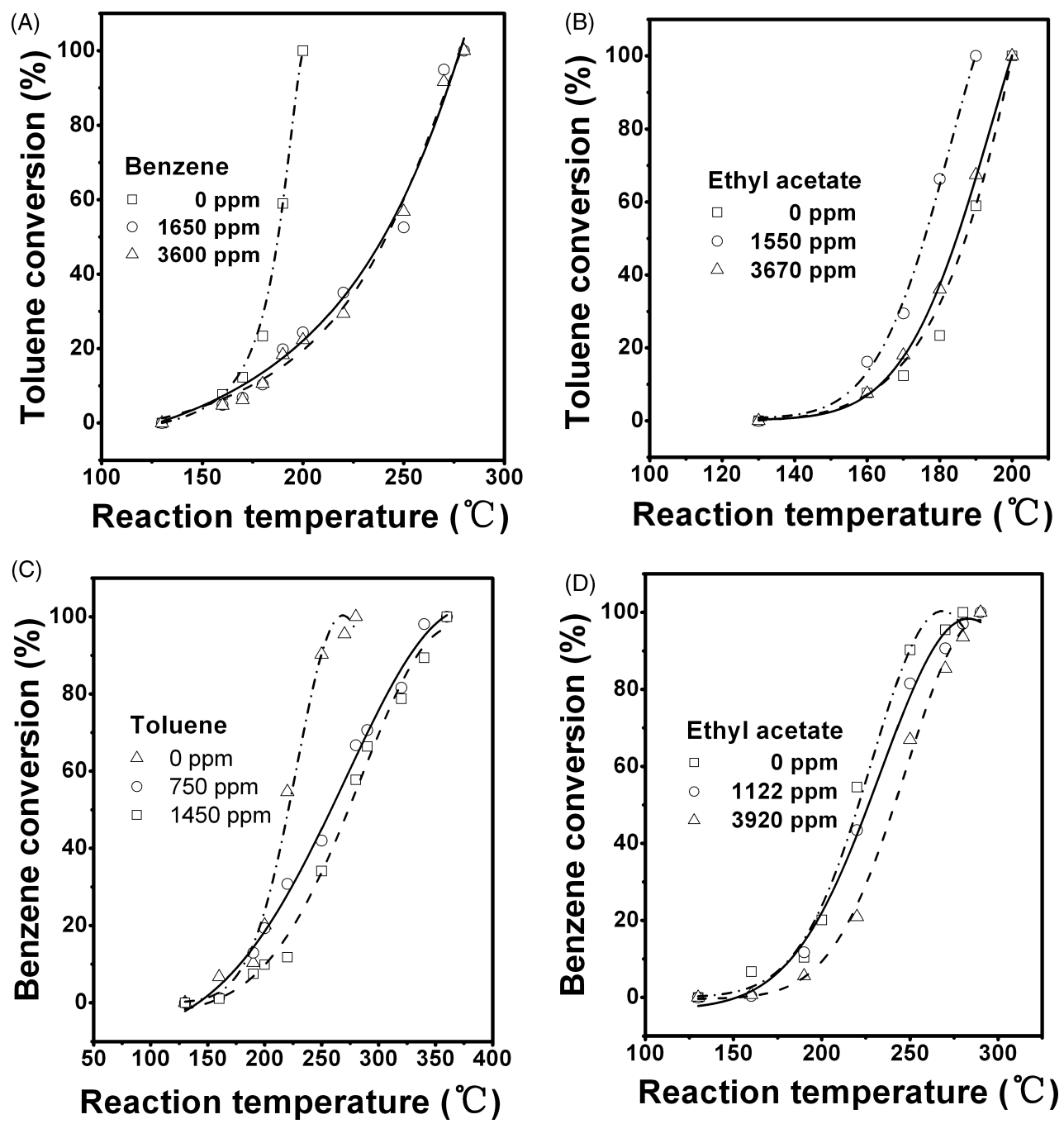

(E)
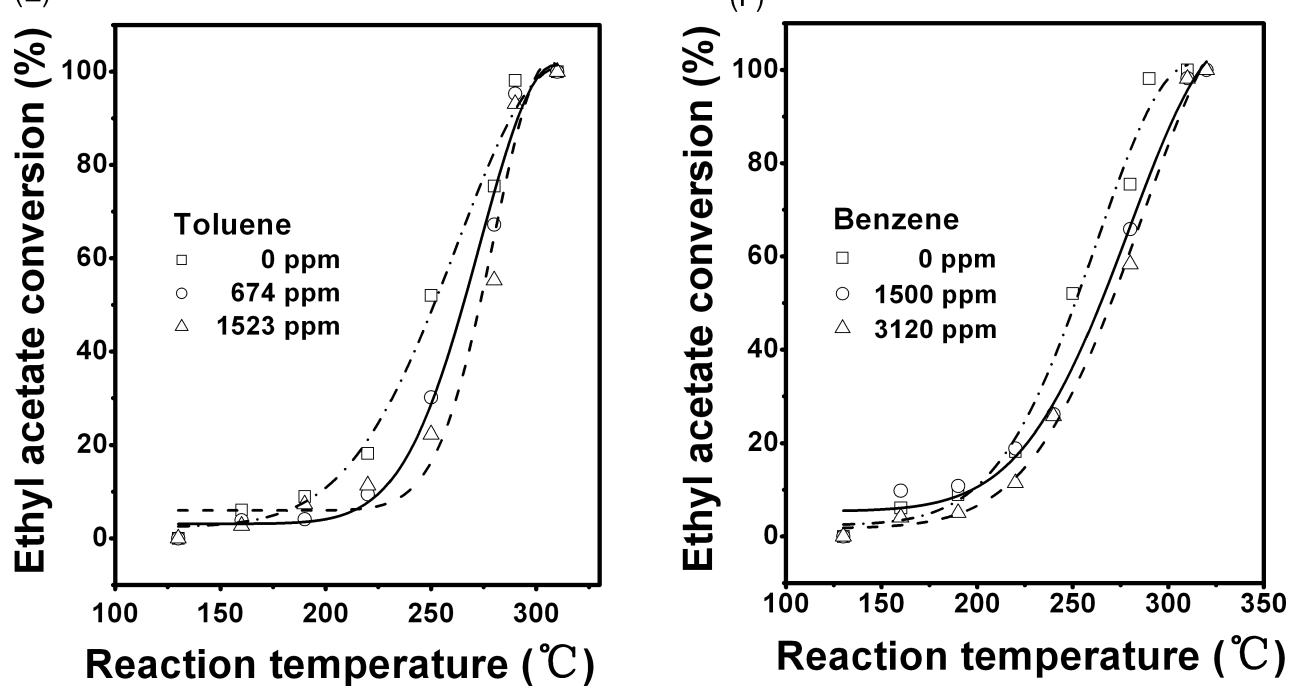

Figure 6. Catalytic oxidation of multicomponent VOCs over Pd/SBA-15 catalyst. (A and B) Conversion of 1500 ppm of toluene in the presence of different concentrations of benzene or ethyl acetate; ( $C$ and D) conversion of 1490 ppm of benzene in the presence of different concentrations of toluene or ethyl acetate; ( $E$ and $F$ ) conversion of 1530 ppm of ethyl acetate in the presence of different concentrations of toluene or benzene. 
concentration. As a consequence, the conversion rate of benzene and toluene is lower at higher inlet concentration, as described in Fig. 5A and B.

\section{Catalytic oxidation of multicomponent mixtures}

VOC mixtures with different compositions and concentrations (Table 1) were fed to the reactor to investigate the mixed effects on oxidation reactions. The total VOC concentrations in all evaluation experiments were in the range of 650-6000 ppm, covering the concentration range of most industrial effluents.

Overall, the conversion of these VOCs decreases to some degree when one of the other two VOCs is present, as shown in Fig. 6. Generally speaking, the presence of other VOC always occupies some active sites over the support through chemisorptions. As a consequence, the concentration of the rate-determinant species decreases. It can be observed that the conversion of ethyl acetate decreases when toluene or benzene is present (Fig. 6E and F), and this behavior can be qualitatively explained considering the higher affinity of the aromatic compounds for the catalyst surface. ${ }^{[31]}$ Figure $6 \mathrm{~A}$ and $\mathrm{C}$ reveals that toluene and benzene possess obvious reciprocal inhibitions. The toluene oxidation is strongly inhibited by the presence of benzene, as $T_{50}$ of toluene increases from 185 to $235^{\circ} \mathrm{C}$ when benzene $(1650 \mathrm{ppm})$ is added, as shown in Fig. 6A. Figure $6 \mathrm{C}$ shows that toluene also possesses an obvious inhibition effect on benzene catalytic oxidation, as $T_{50}$ of benzene increases about $45^{\circ} \mathrm{C}$ (from 225 to $\left.270^{\circ} \mathrm{C}\right)$ when toluene $(1450 \mathrm{ppm})$ is added. As for ethyl acetate, it has a small inhibitory effect on the conversion of benzene (Fig. 6D), as $T_{50}$ of benzene increases from 225 to $240{ }^{\circ} \mathrm{C}$ after adding $3920 \mathrm{ppm}$ of ethyl acetate. However, it is interested to note that ethyl acetate has a small promotion effect on toluene oxidation. Figure 6B shows that toluene has lower conversion temperature after adding different concentrations of ethyl acetate, as $T_{50}$ of toluene decreased from 188 to 183 , and $175^{\circ} \mathrm{C}$ when 3670 and $1550 \mathrm{ppm}$ of ethyl acetate are added, respectively.

In order to further explore the promotion effect of ethyl acetate on toluene oxidation, the conversion of toluene in the presence of both benzene and ethyl acetate was further investigated, as shown in Fig. 7. The profiles show that toluene has a much lower $T_{50}\left(175^{\circ} \mathrm{C}\right)$ than the conversion of single toluene $\left(188^{\circ} \mathrm{C}\right)$ after feeding $1590 \mathrm{ppm}$ of ethyl acetate. It is noteworthy that toluene also possesses a little lower conversion temperature $\left(T_{50}=184^{\circ} \mathrm{C}\right)$ after feeding $710 \mathrm{ppm}$ of benzene and $1740 \mathrm{ppm}$ of ethyl acetate although benzene can strongly inhibit the toluene conversion (Fig. 6A). When the ethyl acetate concentration

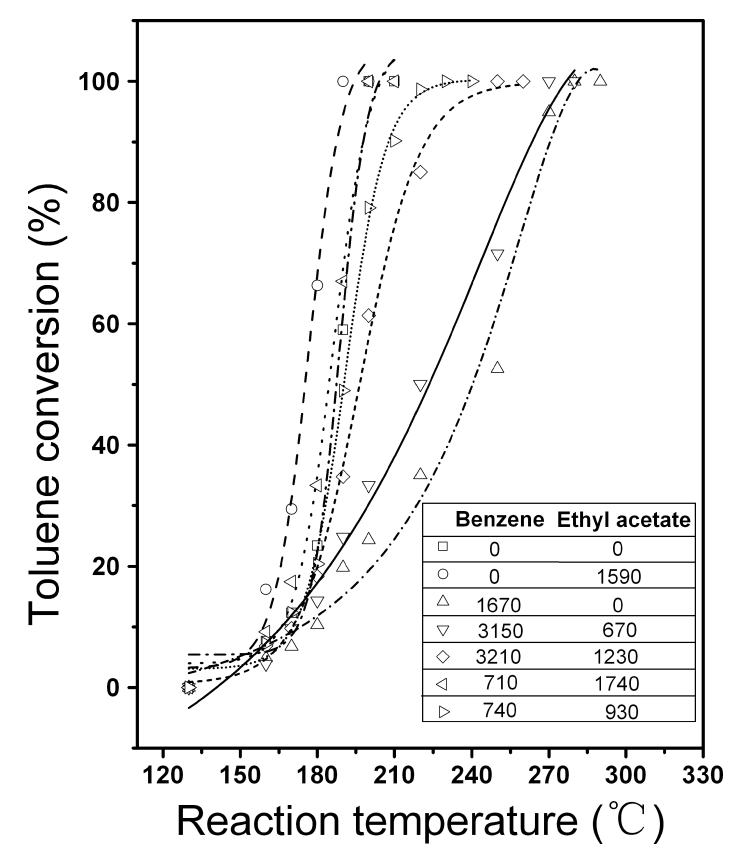

Figure 7. Evolution of toluene conversion in the presence of different concentrations of benzene and ethyl acetate (the VOC units were ppm).

decreases to $930 \mathrm{ppm}$ with the same benzene concentration $(740 \mathrm{ppm})$, the toluene profile is slightly moves to the right side. However, the toluene conversion profile moves much further to the right side when further increases the benzene concentration or decreases the ethyl acetate concentration, and the $T_{50}$ temperatures are higher than that of pure toluene, as shown in Fig. 7.

\section{Kinetic model for VOCs oxidation}

All kinetic experiments were conducted under oxygenrich conditions and the kinetic data were obtained at the conversion below 25\%.[36] The VOC conversion and reaction rate $\left(-r_{i}\right)$ were calculated by the following equations:

$$
\begin{aligned}
\text { VOC conversion } & =\frac{C_{\mathrm{in}}-C_{\mathrm{out}}}{C_{\mathrm{in}}} \times 100 \% \\
-r_{i} & =\frac{F_{\mathrm{A} 0}}{V_{\mathrm{R}}}\left(\frac{C_{\mathrm{in}}-C_{\mathrm{out}}}{C_{\mathrm{in}}}\right)
\end{aligned}
$$

where $C_{\text {in }}$ and $C_{\text {out }}$ are the inlet and outlet VOCs concentrations $(\mathrm{ppm}),-r_{i}$ is the reaction rate $\left(\mathrm{mol} / \mathrm{s} \cdot \mathrm{cm}^{3}\right)$, $F_{\mathrm{A} 0}$ and $V_{\mathrm{R}}$ are the molar flow rate of VOCs $(\mathrm{mol} / \mathrm{s})$ and catalyst volume $\left(\mathrm{cm}^{3}\right)$, respectively.

Several kinetic models could be used to describe the kinetics of deep combustion of VOC compounds, such as Power-law kinetic model, Langmuir-Hinshelwood kinetic model, and Mars-van Krevelen kinetic model. Among these models, the Mars-van Krevelen kinetic 
Table 3. Kinetic constants of oxidation of benzene, toluene, and ethyl acetate.

\begin{tabular}{lccccr}
\hline Compound & $k_{\mathrm{oo}}\left(\mathrm{s}^{-1}\right)$ & $E_{o}(\mathrm{~kJ} / \mathrm{mol})$ & $k_{\text {oi }}^{\prime}\left(\mathrm{s}^{-1}\right)$ & $E_{\mathrm{i}}(\mathrm{kJ} / \mathrm{mol})$ & $r^{2}$ \\
\hline Benzene & $1.0 \times 10^{7}$ & 73.7 & $4.65 \times 10^{10}$ & 91.4 & $>0.999$ \\
Toluene & $4.42 \times 10^{6}$ & 56.8 & $7.82 \times 10^{9}$ & 81.2 & $>0.998$ \\
Ethyl acetate & $1.88 \times 10^{10}$ & 99.8 & $3.19 \times 10^{14}$ & 131.8 & $>0.994$ \\
\hline
\end{tabular}

model was usually preferred for VOC catalytic oxidation over metal oxides ${ }^{[41-43]}$ and supported noble metals (such as Pd catalysts). ${ }^{[4,31,44,45]}$ As a consequence, the Mars-van Krevelen kinetic model was adopted in this work. Mars-van Krevelen kinetic model is based on the assumption of reaction occurs when reactant molecules interact with an oxygen-rich portion of the catalyst. ${ }^{[33,42]}$ The form of the oxygen in the catalyst could be either chemisorbed or lattice oxygen. ${ }^{[41]} \mathrm{A}$ particular portion of the catalyst surface is alternately reduced and oxidized. The $\mathrm{H}_{2}$-TPR result indicates that that $\mathrm{Pd}^{2+}$ gets reduced easily to $\mathrm{Pd}^{0}$ in $\mathrm{H}_{2}$ atmosphere (Fig. 2D). Thus, when $\mathrm{O}_{2}$ is present in the reactant feed mixture, a portion of $\mathrm{Pd}^{0}$ getting oxidized to $\mathrm{PdO}$, and subsequently reduced by the HCs. As a consequence, both the $\mathrm{Pd}^{0}$ and $\mathrm{PdO}$ are responsible for the oxidation reaction. The two-stage redox model postulates two steps:

(a) Reduction of the oxidized catalyst by VOCs:

$$
\text { Reactant }+ \text { Cat-O } \stackrel{k_{i}}{\longrightarrow} \mathrm{Cat}+\mathrm{CO}_{2}
$$

(b) Oxidation of the catalyst by oxygen from the gas phase:

$$
\alpha \mathrm{O}_{2}+2 \mathrm{Cat} \stackrel{k_{o i}}{\longrightarrow} 2 \mathrm{Cat}-\alpha \mathrm{O}
$$

where $k_{i}$ is the kinetic constant for the reaction between chemisorbed oxygen and hydrocarbon, $k_{\mathrm{oi}}$ is the kinetic constant for the nonequilibrium dissociative adsorption of oxygen on catalyst surface, and $\alpha$ is the stoichiometric coefficient for total combustion reaction $\left(\mathrm{mol} \mathrm{O}_{2} / \mathrm{mol}\right.$ of VOC).

In a steady state, the rates of oxidation and reduction should be equal, considering the overall stoichiometry of the reaction $(\alpha)$. The reaction rate $\left(-r_{i}\right)$ is expressed by:

$$
\frac{1}{-r_{i}}=\frac{\alpha}{k_{\mathrm{oi}} C_{\mathrm{oi}}}+\frac{1}{k_{i} C_{i}}
$$

In addition, both the kinetic constants follow an Arrhenius law dependence on temperature:

$$
\begin{gathered}
k_{\mathrm{oi}}=k_{\mathrm{oo}} \exp \left(\frac{-E_{o}}{R T}\right) \\
k_{i}=k^{\prime}{ }_{\mathrm{oi}} \exp \left(\frac{-E_{i}}{R T}\right)
\end{gathered}
$$

(C) 2011 Curtin University of Technology and John Wiley \& Sons, Ltd. where $C_{\mathrm{oi}}$ is the $\mathrm{O}_{2}$ concentrations of $\left(\mathrm{mol} / \mathrm{cm}^{3}\right), C_{i}$ is the VOCs concentrations $\left(\mathrm{mol} / \mathrm{cm}^{3}\right), k_{\mathrm{oo}}$ and $k_{\mathrm{oi}}^{\prime}$ are the pre-exponential factors $(1 / \mathrm{s}), E_{o}$ and $E_{i}$ are the reaction activation energy $(\mathrm{kJ} / \mathrm{mol}), R$ and $T$ are the gas constant $(8.31 \mathrm{~J} / \mathrm{mol} \cdot \mathrm{K})$ and reaction temperature (K), respectively.

The parameter values for benzene, toluene, and ethyl acetate studied in this work are shown in Table 3, and all the Arrhenius plots of the reaction rate are depicted in Fig. 8A. The values of the correlation coefficient $\left(r^{2}\right)$ are higher than 0.99 in all cases. Moreover, a series of data were obtained to verify the accuracy of the kinetic models by predicting the reaction rate at different VOC feed concentrations, as shown in Fig. 8B (experimental conversions $v s$ that of predicted). It can be observed that all these VOCs can be fitted by the Mars-van Krevelen model, especially in the case of benzene and ethyl acetate. On the other hand, regarding the values of $k_{\mathrm{oi}}$, it is important to note that this parameter should be independent of the VOCs that is oxidized according to the postulates of the Mars-van Krevelen model. This is approximately true for benzene $\left(k_{\mathrm{oo}}=1.0 \times 10^{7}\right)$ and toluene $\left(k_{\mathrm{oo}}=4.42 \times 10^{6}\right)$, while the calculated $k_{\mathrm{oi}}$ value for ethyl acetate $\left(k_{\mathrm{oo}}=1.88 \times 10^{10}\right)$ is much higher than that of aromatics. Similar behavior was observed by other investigators in VOC combustion, and they suggested the metal in the catalyst can possesses different reduction states, depending on the oxidized hydrocarbons. ${ }^{[31,41,45]}$ The values of the model parameters suggest the various behaviors of aromatics and ethyl acetate. The values of $k_{i}$ are very similar for benzene and toluene (pre-exponential values: benzene $\left(4.65 \times 10^{10}\right)$, toluene $\left.\left(7.82 \times 10^{9}\right)\right)$, whereas for ethyl acetate, the value of $k_{\text {oi }}^{\prime}\left(3.19 \times 10^{14}\right)$ is almost four orders magnitude higher than that of aromatics, and the activation energy of ethyl acetate is also higher, as shown in Table 3.

\section{CONCLUSIONS}

The reaction behaviors and kinetics of deep catalytic oxidation of three typical VOCs (benzene, toluene and ethyl acetate) were comprehensively investigated over mesoporous Pd/SBA-15. Reaction behavior of single VOC reveals that toluene is the most active component, followed by ethyl acetate and benzene. The conversion of toluene and benzene reduces continuously 
(A)

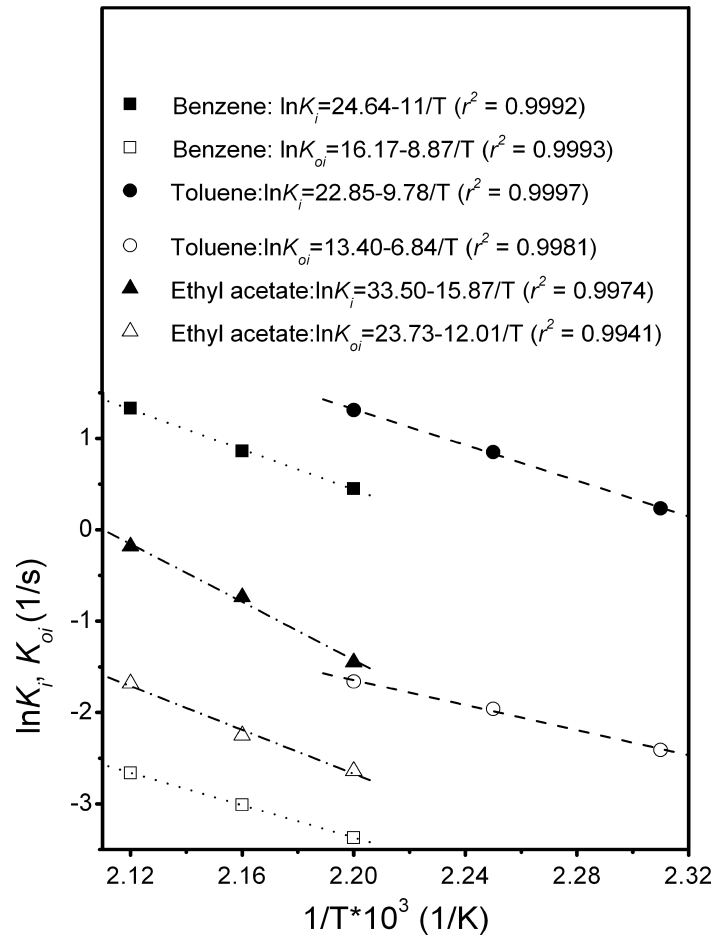

(B)
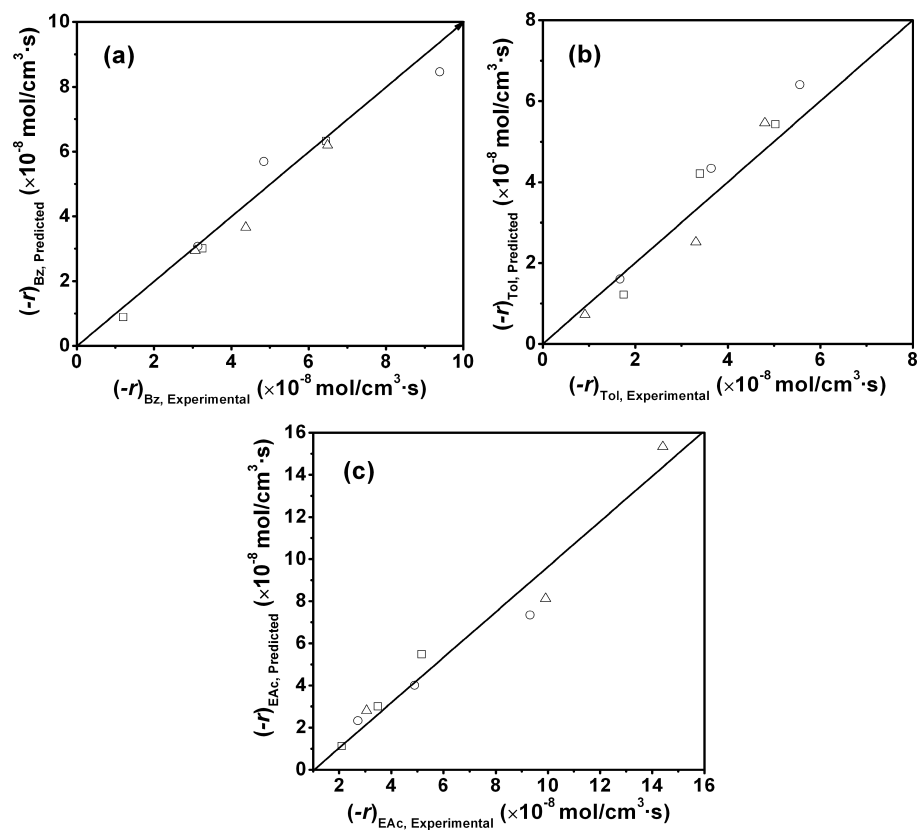

Figure 8. (A) Arrhenius plots of the rate constant. (B) Predicted vs experimental conversion for VOC oxidation with the Mars-van Krevelen kinetic model: (a) different concentrations of benzene ( $\square: 880 \mathrm{ppm}, 0: 1600 \mathrm{ppm}, \triangle: 3610 \mathrm{ppm})$; (b) different concentrations of toluene ( $\square: 690$ ppm, o: 1015 ppm, $\Delta: 1550$ ppm); (c) different concentrations of ethyl acetate ( $\square: 970$ ppm, o: 1530 ppm, $\Delta: 3670$ ppm).

when their inlet concentrations are increased, while this phenomenon is not observed for ethyl acetate catalytic oxidation. As for VOC mixtures, benzene and toluene inhibits each other during their oxidation reactions, and the presence of aromatic compounds inhibits the combustion of ethyl acetate. Ethyl acetate has a promotion effect on toluene oxidation, while the opposite behavior is observed for benzene combustion. The Mars-van Krevelen model can well predict the conversion behaviors of all investigated VOCs, especially for benzene and ethyl acetate.

\section{Acknowledgments}

National Science Fund for Distinguished Young Scholars (No. 20725723) and National High Technology Research and Development Program of China (No. 2006AA06A310) are gratefully acknowledged.

\section{REFERENCES}

[1] J.C. Lou, S.W. Huang. Environ. Eng. Sci., 2009; 26, 579-588.

[2] C. He, J.J. Li, P. Li, J. Cheng, Z.P. Hao, Z.-P. Xu. Appl. Catal. B: Environ., 2010; 96, 466-475.

[3] J.J. Li, X.Y. Xu, Z. Jiang, Z.P. Hao, C. Hu. Environ. Sci. Technol., 2005; 39, 1319-1323.

(C) 2011 Curtin University of Technology and John Wiley \& Sons, Ltd.
[4] A.A. Barresi, G. Baldi. Ind. Eng. Chem. Res., 1994; 33, $2964-2974$

[5] J.J. Li, Z. Jiang, Z.P. Hao, X.Y. Xu, Y.H. Zhuang. J. Mol. Catal. A: Chem., 2005; 225, 173-179.

[6] S. Vigneron, P. Deprelle, J. Hermia. Catal. Today, 1996; 27, 229-236.

[7] R.K. Sharma, B. Zhou, S. Toung, K. Chuang. Ind. Eng. Chem. Res., 1995; 34, 4310-4317.

[8] C. He, P. Li, J. Cheng, H.L. Wang, J.J. Li, Q. Li, Z.P. Hao. Appl. Catal. A: Gen., 2010; 382, 167-175.

[9] N. Li, F. Gaillard. Appl. Catal. B: Environ., 2009; 88, $152-159$

[10] Q. Liu, L.C. Wang, M. Chen, Y. Cao, H.Y. He, K.N. Fan. J Catal., 2009; 263, 104-113.

[11] D. Delimaris, T. Ioannides. Appl. Catal. B: Environ., 2008; 84, $303-312$.

[12] S.F. Zuo, R.X. Zhou. Micropor. Mesopor. Mater., 2008; 113, $472-480$.

[13] T. Mishra, P. Mohapatra, K.M. Parida. Appl. Catal. B: Environ., 2008; 79, 279-285.

[14] C. He, P. Li, J.J. Li, H.L. Wang, J. Cheng, X.Y. Zhang, Z.P. Hao. J. Hazard. Mater., 2010; 181, 996-1003.

[15] A. Orlov, J. Klinowski. Chemosphere, 2009; 74, 344-348.

[16] K. Bendahou, L. Cherif, S. Siffert, H.L. Tidahy, H. Benä̈ssa, A. Aboukaïs. Appl. Catal. A: Gen., 2008; 351, 82-87.

[17] M. Popova, Á. Szegedi, P. Németh, N. Kostova, T. Tsoncheva. Catal. Commun., 2008; 10, 304-308.

[18] M. Guillemot, J. Mijoin, S. Mignard, P. Magnoux. Appl. Catal. A: Gen., 2007; 327, 211-217.

[19] T. Williams, J. Beltramini, G.Q. Lu. Micropor. Mesopor. Mater., 2006; $88,91-100$.

[20] C. He, Q. Li, P. Li, Y.F. Wang, X.Y. Zhang, J. Cheng, Z.P. Hao. Chem. Eng. J., 2010; 162, 901-909.

[21] T. Garcia, B., Solsona, D.M. Murphy, K.L. Antcliff, S.H. Taylor. J. Catal., 2005; 229, 1-11. 
[22] T. Garcia, B. Solsona, D. Cazorla-Amoros, A. LinaresSolano, S.H. Tayor. Appl. Catal. B: Environ., 2006; 62: $66-76$.

[23] T. Tsoncheva, L. Ivanova, J. Rosenholm, M. Linden. Appl. Catal. B: Environ., 2009; 89, 365-374.

[24] K.J. Kim, H.G. Ahn. Appl. Catal. B: Environ., 2009; 91, $308-318$.

[25] A.M. Venezia, G. Di Carlo, G. Pantaleo, L.F. Liotta, G. Melaet, N. Kruse. Appl. Catal. B: Environ., 2009; 88, 430-437.

[26] F.N. Aguero, B.P. Barbero, L. Gambaro, L.E. Cadus. Appl. Catal. B: Environ., 2009; 91, 108-112.

[27] K. Okumura, T. Kobayashi, H. Tanaka, M. Niwa. Appl. Catal. B: Environ., 2003; 44, 325-331.

[28] C. He, P. Li, J. Cheng, Z.P. Hao, Z.-P. Xu. Water Air Soil Pollut., 2010; 209, 365-376.

[29] J. Deutsch, H.A. Prescott, D. Muller, E. Kemnitz. J. Catal., 2005; 231, 269-278.

[30] J.N. Park, A.J. Forman, W. Tang, J.H. Cheng, Y.S. Hu, H.F. Lin, E.W. McFarland. Small, 2008; 4, 1694-1697.

[31] S. Ordóñez, L. Bello, H. Sastre, R. Rosal, F.V. Díez. Appl. Catal. B: Environ. 2002; 38, 139-149.

[32] L.M. Gandía, A. Gil, S.A. Korili. Appl. Catal. B: Environ., 2001; 33, 1-8.

[33] A.Z. Abdullah, M.Z.A. Bakar, S. Bhatia. Ind. Eng. Chem. Res., 2003; 42, 6059-6067.
[34] P. Papaefthimiou, T. Ioannides, X.E. Verykios. Appl. Catal. B. Environ., 1997; 13, 175-184.

[35] J.J. Spivey. Ind. Eng. Chem. Res., 1987; 26, 2165-2180.

[36] C.G. Hill. An Introduction to Chemical Engineering Kinetics and Reactor Design, John Wiley \& Sons: New York, 1977; p.90.

[37] Z. Mu, J.J. Li, H. Tian, Z.P. Hao, S.Z. Qiao. Mater. Res. Bull., 2008; 43, 2599-2606.

[38] K.S.W. Sing, D.H. Everett, R.A.W. Haul, L. Moscou, R.A. Pierotti, J. Rouquerol, T. Siemieniewska. Pure Appl. Chem., 1985; 57, 603-619.

[39] L.M. Gomez-Sainero, X.L. Seoane, J.L.G. Fierro, A. Arcoya. J. Catal., 2002; 209, 279-288.

[40] M. Bonarowska, J. Pielaszek, V.A. Semikolenov, Z. Karpinski. J. Catal., 2002; 209, 528-538.

[41] S. Dangi, M.A. Abraham. Ind. Eng. Chem. Res., 1997; 36, 1979-1988.

[42] A.A. Barresi, I. Mazzarino, G. Baldi. Can. J. Chem. Eng., 1992; 70, 286-293.

[43] C. He, J.J. Li, J. Cheng, L.D. Li, P. Li, Z.P. Hao, Z.P. Xu. Ind. Eng. Chem. Res., 2009; 48, 6930-6936.

[44] J. Downie, K.A. Shelstad, W.F. Graydon. Can. J. Chem. Eng., 1961; 39, 201-204.

[45] S.K. Gangwal, M.E. Mullis, J.J. Spivey, P.R. Caffrey. Appl. Catal., 1988; 36, 231-247. 